Research Paper

\title{
Agonist of PPAR-y Reduced Epithelial-Mesenchymal Transition in Eosinophilic Chronic Rhinosinusitis with Nasal Polyps via Inhibition of High Mobility Group Boxl
}

\author{
Pingli Yang ${ }^{1,3}$, Shan Chen ${ }^{1}$, Gang Zhong1, Weijia Kong1,2® ${ }^{\circledR}$ Yanjun Wang ${ }^{1 凶}$ \\ 1. Department of otorhinolaryngology, Union Hospital, Tongji Medical College, Huazhong University of Science and Technology, Wuhan, 430022, China \\ 2. Institutes of Otorhinolaryngology, Union Hospital, Tongji Medical College, Huazhong University of Science and Technology, Wuhan, 430022, China \\ 3. Department of otorhinolaryngology, The First Affiliated Hospital, Shihezi University School of Medicine, Shihezi, Xinjiang, 832000, China
}

$\square$ Corresponding author: Weijia Kong, Department of Otorhinolaryngology, Union Hospital, Tongji Medical College, Huazhong University of Science and Technology, 1277 Jiefang Avenue, Wuhan 430022, China, Fax:+86-27-85776343; Tel:+86-13995569997; E-mail: entwjkong@hust.edu.cn or Yanjun Wang, Department of Otorhinolaryngology, Union Hospital, Tongji Medical College, Huazhong University of Science and Technology, 1277 Jiefang Avenue, Wuhan 430022, China, Fax:+86-27-87543437; Tel:+86-13971235668; E-mail: yanjunwangent@163.com

(c) The author(s). This is an open access article distributed under the terms of the Creative Commons Attribution License (https://creativecommons.org/licenses/by/4.0/). See http://ivyspring.com/terms for full terms and conditions.

Received: 2019.04.22; Accepted: 2019.10.29; Published: 2019.11.09

\begin{abstract}
Epithelial-mesenchymal transition (EMT) has been reported to occur in eosinophilic chronic rhinosinusitis with nasal polyps (ECRSwNP). Among the cytokines that cause EMT, high mobility group box 1 (HMGB1) has been shown to give rise to EMT in airway epithelial cells. However, the mechanism of HMGBI-induced EMT in ECRSwNP is unknown. We explored the mechanism and possible inhibitor. Immunohistochemistry (IHC), immunofluorescence (IF), and western blot assay were used to detect the expression and location of HMGBI, peroxisome proliferator-activated receptor-Y (PPAR-Y), and EMT markers in eighteen ECRSwNP and twelve normal nasal mucosa tissues. Epithelial cells isolated from ECRSwNP were cultured with various doses of recombinant human HMGBI (rhHMGBI) to study the expression of PPAR- $y$, and EMT markers. Additionally, the ligand of PPAR- $y$ was incubated with epithelial cells to interfere with the effects of lipopolysaccharide (LPS) or rhHMGBI to explore the effect on expression of HMGBI and EMT markers. These results suggest that HMGBI was highly expressed in ECRSwNP compared with its expression in control tissues, and EMT was also found highly in ECRSwNP compared with control tissues. Moreover, the cytoplasmic accumulation of HMGBI in ECRSwNP was obvious compared with normal tissues. We also found dose-dependent induction by rhHMGBI of up-regulation of $\mathrm{N}$-cadherin and vimentin and down-regulation of ZO-1 and E-cadherin in epithelial cells isolated from ECRSwNP. The agonist of PPAR-Y not only reduced release of HMGBI induced by LPS, but also reversed the EMT. The protective role of PPAR- $y$ also appeared in cells that had been incubated with rhHMGBI. In the current study, we discovered that the agonist of PPAR-y has a potential role in inhibited HMGB1-induced EMT in ECRSwNP. The agonist of PPAR- $\gamma$ may contribute to inhabit epithelial cells to become mesenchymal-like cells which play an important role in the pathogenesis of ECRSWNP.
\end{abstract}

Key words: Epithelial-mesenchymal transition; chronic rhinosinusitis with nasal polyps; high mobility group box 1 ; peroxisome proliferator-activated receptor- $\gamma$

\section{Introduction}

Chronic rhinosinusitis with nasal polyps (CRSwNP) is characterized by an intensely edematous stroma with formation of pseudocysts, infiltration of subepithelial and perivascular inflammatory cells, and albumin deposition [1]. Phenotyping classification of CRSwNP was inappropriate nowadays because it is not adequately reflect the pathophysiologic diversity, while 
endotype, based on the pathogenesis is more helpful for the diagnosis and treatment for CRSwNP [2]. Endotype, which was defined by different pathogenic mechanisms, currently being accepted by many authors for it is correlate with the disease's clinical manifestations and behavior [3-5]. Based on endotype, regardless of racial backgrounds, geographic areas and populations, CRSwNP can be divided into eosinophilic (ECRSwNP), when the nasal mucosa shows considerable eosinophilic infiltration, and non-eosinophilic (nonECRSwNP), when it does not [6-9]. The two types of CRSwNP show different patterns of inflammation and tissue remodeling. About the changes in inflammation patterns, ECRSwNP show eosinophilic inflammation with typical type 2-biased immune response, whereas nonECRSwNP demonstrates type 1/type 3 predominant immune responses and it also shows a few eosinophils compared with CRSsNP [10]. Type 2-biased immune responses are featured by upregulated production of IL-4, IL-5, IL-13 and local IgE [11]. IL-5 regulates the activity of eosinophils and there are positive interactions between them [12]. As regard to tissue remodeling, basement membrane was thicker and squamous metaplasia of epithelium was more frequently in eosinophilic inflammation [13]. In previous studies, HMGB1 has been shown to support the survival of eosinophilic granulocytes [14] and has been confirmed to relate to tissue remodeling, such as in COPD $[15,16]$. Extracellular HMGB1 amplifies inflammatory and remodeling signals through binding to RAGE or other possibly partners into target cells while intranuclear HMGB1 could be released to target cells too. Luisa et al. found that HMGB1 translocated from nuclei to cytoplasm and observed a positive relationship between HMGB1 and eosinophil scores after stimulating with lipopolysaccharide (LPS) in human nasal epithelial cells, suggesting that HMGB1 plays an important role in ECRSwNP [17], but the mechanism of the relationship between HMGB1 and formation of nasal polyp in ECRSwNP is unclear.

HMGB1 is a pro-inflammatory DNA-binding nuclear protein. It can initiate and promote inflammatory cytokine synthesis by forming complexes with pro-inflammatory molecules when actively secreted by immune cells after exposure to a danger signal or when passively released by dead or dying cells $[15,18]$. Previous studies showed that HMGB1 induces epithelial-mesenchymal transition (EMT) in airway epithelial tissue $[19,20]$. EMT, the transition of epithelial and endothelial cells to a motile phenotype, namely, transformation to mesenchymal stem cells, which not only associated with embryonic development, inflammation, tissue regeneration, and tumor formation, but also play an important role in the pathogenesis of ECRSwNP [21-23]. At the molecular level, epithelial cells lose their epithelial character and gain mesenchymal properties. Associated changes are the down-regulation of epithelial markers such as ZO-1 and E-cadherin, and the up-regulation of mesenchymal markers such as vimentin and $\mathrm{N}$-cadherin [24]. We speculate that HMGB1 and eosinophils promote each other and cause the acceleration of the EMT process, thus playing an important role in the pathogenesis of ECRSwNP.

Peroxisome proliferator-activated receptor- $\gamma$ (PPAR- $\gamma$ ) is a member of a class of PPARs that can be activated by specific PPAR- $\gamma$ ligands in the cytoplasm. Numerous studies have demonstrated that PPAR- $\gamma$ activated by ligands can suppress such biological functions of HMGB1 as extracellular release, gene expression, and signaling pathways [25-27]. PPAR- $\gamma$ ligands contain fibrates, thiazolidinediones, and eicosanoids [28]. Rosiglitazone (ROG), an antidiabetic drug belonging to the thiazolidinedione class, has been reported to be involved in the inhibition of LPS-induced HMGB1 release in RAW264.7 cells via activated PPAR- $\gamma$ [29]. Therefore, we speculated that the agonist of PPAR- $\gamma$ may reduce HMGB1-induced EMT in ECRSwNP.

\section{Materials and Methods}

\section{Patient tissue samples}

Eighteen ECRSwNP tissue samples named experimental group and twelve normal nasal mucosa tissue samples named control were obtained from the Department of Otolaryngology, Union Hospital (Wuhan, China) between January and December 2018. ECRSwNP samples were classified as such when the number of eosinophils counted at high-power field (HPF) $(\times 400)$ exceeded 10, after 10 high-power fields were randomly selected and analyzed. Tissues of ECRSwNP were diagnosed as nasal polyps by the Department of Pathology at Union Hospital, whereas normal nasal mucosa tissues were obtained from patients who required partial excision of the turbinate, uncinate process and ethmoidal mucosa for surgical purposes, for example deviated nasal septum, or intracranial access. Each tissue was divided into three parts, one of it was reserved for cell culture, one of it was fixed for immunohistochemistry (IHC) and immunofluorescence (IF) evaluation using formalin for paraffin section or frozen section, and the last one stored at $-80^{\circ} \mathrm{C}$ for protein extraction. We obtained informed consent from each patient and the study protocol was approved by the research ethics committee of Tongji Medical College, Huazhong 
University of Science and Technology (Permit Number: S440).

\section{Isolation of primary human nasal epithelial cells}

Tissue samples of ECRSwNP of approximately 1 $\mathrm{ml}$ volume were rinsed with normal saline, transferred into $10 \mathrm{ml}$ of DMEM/F12 medium containing $1 \%$ penicillin/streptomycin (Hyclone, USA), and digested with $0.1 \%$ protease from Streptomyces griseus (9036-06-0, CAS, USA) and 0.1 $\mathrm{mg} / \mathrm{ml}$ deoxyribonuclease (D5025, Sigma, USA), and incubated at $4^{\circ} \mathrm{C}$ overnight. Epithelial cells were removed by gently scraping and blow them into single cell to the greatest extent. The medium was then transferred into a 15-ml conical tube, centrifuged at $1500 \mathrm{rpm}$ for $5 \mathrm{~min}$, the supernatant decanted, and the pellet resuspended in DMEM/F12 medium. Primary cells were plated on collagen type IV (Sigma)-coated 12-well culture plates with density of $2 \times 10^{5}$ cells/well for protein extraction and on 24-well culture plates with density of $1 \times 10^{5}$ cells/well for IF, and then cultured at $37^{\circ} \mathrm{C}$ in $5 \% \mathrm{CO} 2$ overnight. The medium was then changed to PneumaCultTM-EX plus Basal Medium (05041, CAT, USA) containing 1\% penicillin/streptomycin. For EMT induction, recombinant human HMGB1 (P09429, Bio-techne, USA) was added into the plates at different doses $(100,300,500 \mathrm{ng} / \mathrm{ml})$ for $48 \mathrm{~h}$. Tissues derived from multiple patients and stimulation experiments consisted of a minimum of three independent experiments.

\section{Immunohistochemical staining}

The tissues were fixed with phosphate buffered saline (PBS) containing 4\% formaldehyde for $24 \mathrm{~h}$ $\left(4^{\circ} \mathrm{C}, \mathrm{pH} 7.3\right)$, dehydrated in a graded ethanol series (70\%, 80\%, 90\%, 95\%, and 100\%), embedded in paraffin, and then sliced into sections of 5- $\mu \mathrm{m}$ thickness and placed on poly-L-lysine-coated glass slides.

The paraffin glass slides of ECRSwNP and control for IHC were deparaffinized and hydrated in a graded ethanol series $(100 \%, 95 \%, 90 \%, 80 \%$, and $70 \%)$, subjected to heat-induced epitope retrieval, washed three times with PBS, and then incubated with $3 \% \quad \mathrm{H}_{2} \mathrm{O}_{2}$ for $10 \mathrm{~min}$ to block endogenous peroxidases. Bovine serum albumin protein was applied to saturate any excess protein-binding sites. The blocked sections were incubated with E-cadherin antibody (GTX100443, diluted 1:200, rabbit polyclonal), vimentin antibody (GTX112661, diluted 1:200, rabbit polyclonal), anti-HMGB1 (ab79823; diluted 1:350, rabbit monoclonal), and anti-PPAR- $\gamma$ (Novusbio, diluted 1:100, rabbit polyclonal) at $4^{\circ} \mathrm{C}$ overnight. After the tissues had been rinsed three times with PBS for 5 min, a two-step immunohistochemical detection kit (G1210-2, Servicebio, Wuhan, China) was used. After incubation with horseradish peroxidase-conjugated secondary antibody and visualization with diaminobenzidine color according to the manufacturer's instructions, the slides were stained with hematoxylin, dehydrated in a graded ethanol series, and xylene transparent. Finally, the slides were observed under a light microscope.

\section{Immunofluorescence}

For immunofluorescence histochemistry, the ECRSwNP and control tissues were fixed with $4 \%$ paraformaldehyde at $4^{\circ} \mathrm{C}$ overnight. After washing, they were gradient transferred into $20 \%, 30 \%$ sucrose in PBS for dehydration and cryoprotection. The tissues were embedded in OCT (Sakura, Tokyo, Japan) and cut into sections with a thickness of $10 \mu \mathrm{m}$ using a cryostat (CM3050s, Leica, Germany). For immunofluorescence cytochemistry, the primary human nasal epithelial cells were incubated with or without rhHMGB1 or ROG in 24-well plates for $48 \mathrm{~h}$. Then, the sections and cells were incubated with blocking solution ( $10 \%$ donkey serum with $0.2 \%$ Triton X-100) for $1 \mathrm{~h}$ at room temperature, then incubated with primary antibody (E-cadherin, vimentin, and HMGB1 for slides and ZO-1 and vimentin for cells) overnight at $4^{\circ} \mathrm{C}$. After rinsing, the sections and cells were incubated with Alexa Fluor 594 Donkey Anti-Rabbit IgG (H+L), diluted 1:200, for $1 \mathrm{~h}$, and counterstained with 4,6-diamidino-2phenylindole (Roche, Shanghai, China) for the staining of nuclei. After washing with PBS, the cover slips were mounted with antifade mounting medium (Beyotime, Shanghai, China) on slides. Images were taken with a laser scanning confocal microscope (Nikon A1-si, Japan). The reconstruction images were produced with the NIS-Element software (Nikon, Japan).

\section{Western blotting}

The protein expression level was examined using western blot. ECRSwNP tissues, control tissues, and incubated cells were dissected and lysed in radioimmunoprecipitation assay lysis solution (Beyotime, Haimen, Jiangsu, China) containing phosphatase inhibitors and PMSF. The protein concentrations were measured using the bicinchoninic acid protein assay kit (Beyotime Haimen, Jiangsu, China). $20 \mu \mathrm{g}$ protein was loaded on $10 \%$ SDS-polyacrylamide gel and it was separated. The proteins in the gel were then transferred to polyvinylidene difluoride membranes, which were incubated in blocking solution (5\% non-fat milk in 
Tris-buffered saline) for $1 \mathrm{~h}$ at room temperature and then incubated overnight at $4^{\circ} \mathrm{C}$ with primary antibodies containing: ZO-1 (GTX108613, CA, USA, rabbit polyclonal), E-cadherin (GTX100443, CA, USA, rabbit polyclonal), N-cadherin (GTX127345, CA, USA, rabbit polyclonal), vimentin (GTX112661, CA, USA, rabbit polyclonal), in a dilution ratio of 1:1000, and HMGB1 (ab79823, Abcam, rabbit monoclonal), in a dilution ratio of $1: 10,000$. The membranes were washed three times with TBST and incubated with secondary antibodies, horseradish peroxidaseconjugated goat anti-rabbit or goat anti-mouse IgG (diluted 1:4000) for $60 \mathrm{~min}$ at room temperature. An electrochemiluminescence kit (Beyotime, Haimen, Jiangsu, China) was used to visualize the membranes. The relative expression level of proteins was represented in the ratio of the target protein and GAPDH using ImageJ 1.51J8 software (National Institutes of Health, USA).

\section{Statistical analyses}

All data were analyzed with SPSS (version 17.0). The measured data were presented as the mean \pm standard deviation. Quantitative data were analyzed using the unpaired Student's $t$-test for comparing two groups and one-way analysis of variance for multiple-variant analyses. A P value of less than 0.05 was considered to indicate a statistically significant difference.

\section{Results}

\section{EMT markers, HMGB 1 and PPAR-Y expression patterns in ECRSwNP and control tissues}

To evaluate the expression of EMT markers, HMGB1, and PPAR- $\gamma$ in ECRSwNP, we performed IHC staining in 18 human ECRSwNP samples and 12 control tissues. IHC analysis of tissue sections revealed that the expression levels of E-cadherin and PPAR- $\gamma$ were down-regulated in the ECRSwNP tissues, whereas those of vimentin and HMGB1 were up-regulated in the ECRSwNP tissues (Fig. 1A). Semiquantitative evaluation of IHC staining was used to detect the expression of E-cadherin, vimentin, HMGB1, and PPAR-y in 18 ECRSwNP and 12 control tissue samples. There were significant differences in expression of E-cadherin $(\mathrm{P}<0.001)$, vimentin $(\mathrm{P}<$ $0.01)$, HMGB1 $(\mathrm{P}<0.05)$ and PPAR- $\gamma(\mathrm{P}<0.05)$ (Fig. 1B). Obvious cytoplasmic staining of HMGB1 was observed in the ECRSwNP tissues compared with the control tissues (Fig. 1C). Confocal microscopy confirmed that the expression of E-cadherin was down-regulated, whereas vimentin was up-regulated in ECRSwNP (Fig. 2A). More cytoplasmic distribution of HMGB1 was found in ECRSwNP tissues (Fig. 2B).

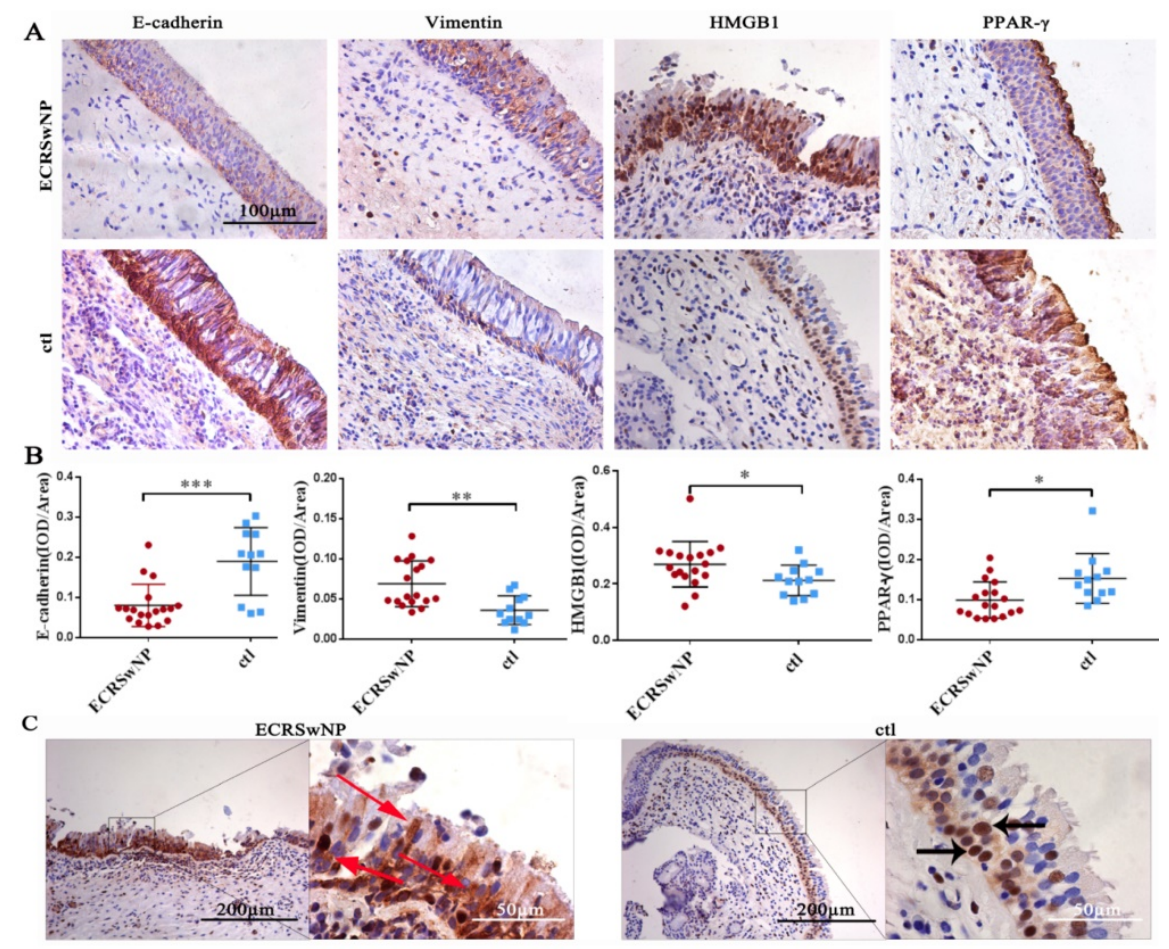

Figure 1. Staining of E-cadherin, vimentin, HMGB I, and PPAR-Y in ECRSwNP and control tissues. (A) Immunohistochemistry assay was performed to detect the staining of E-cadherin, vimentin, HMGB1, and PPAR- $\gamma$ in ECRSwNP and control tissues. Bar, $100 \mu \mathrm{m}$. (B) The expression of E-cadherin, vimentin, HMGB1, and PPAR- $y$ in ECRSwNP and control tissues was determined by immunohistochemical semi-quantification. Data were represented as the mean \pm SD (standard deviation). $* \mathrm{P}<0.05, * * \mathrm{P}<0.01$, $* * * \mathrm{P}<0.001$. ECRSwNP $(n=18)$, ctl $(n=12)$. (C) The location of HMGB1 in ECRSwNP and control tissues. Black bar, $200 \mu \mathrm{m}, \mathrm{white}$ bar, $50 \mu \mathrm{m}$. The red arrows showed the location of HMGB1 in the cytoplasm. The black arrows showed the location of HMGB1 in the nucleus. 

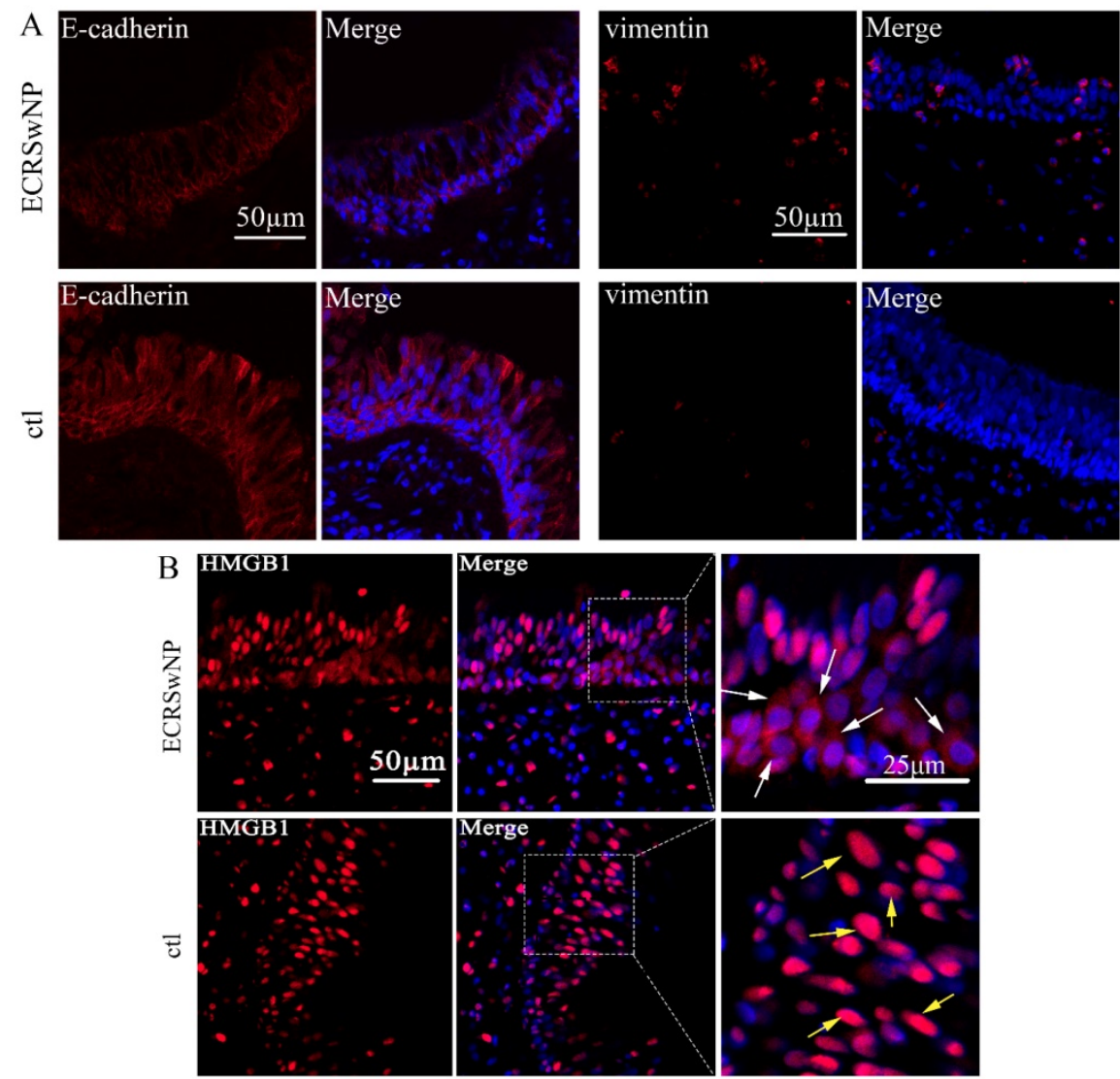

Figure 2. Expression of E-cadherin, vimentin, and HMGB1 in ECRSWNP and control tissues. (A) Confocal microscopic examination of E-cadherin and vimentin in ECRSwNP and control tissues. Bar, $50 \mu \mathrm{m}$. (B) Expression and location of HMGB1. The white arrows showed the location of HMGB1 in the cytoplasm. The yellow arrows showed the location of HMGB1 in the nucleus. Left bar, $50 \mu \mathrm{m}$, right bar, $25 \mu \mathrm{m}$.
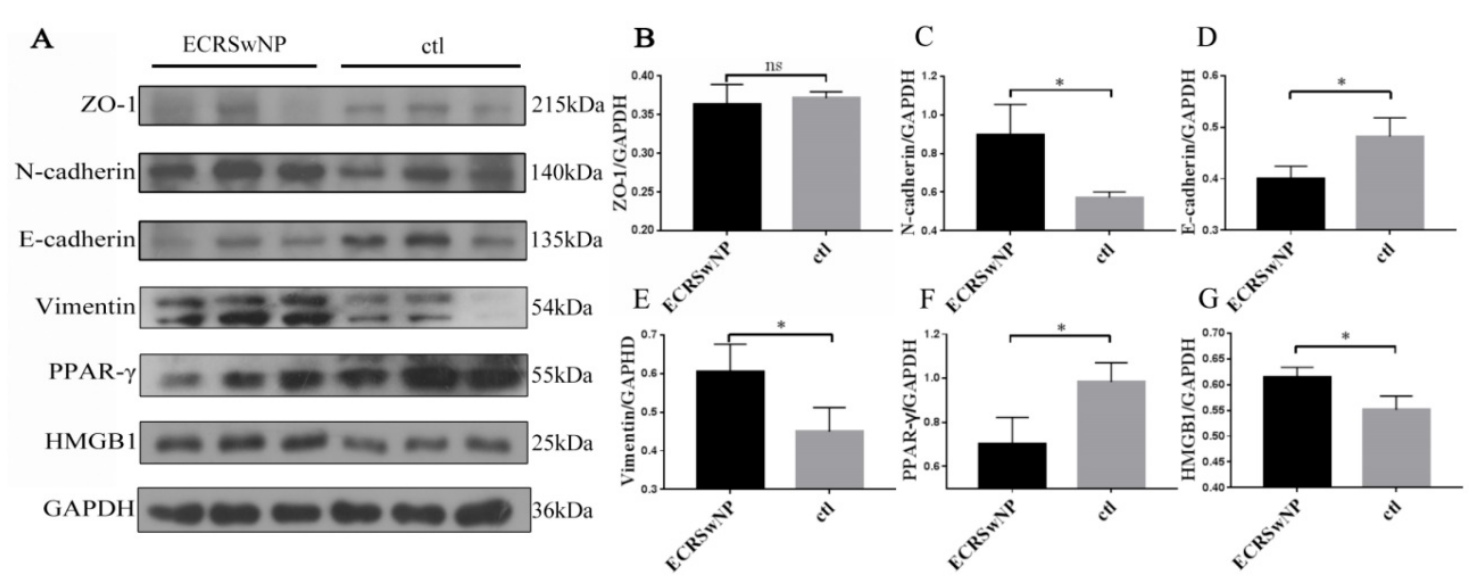

Figure 3. Expression of EMT markers in ECRSwNP and ctl tissues. (A) The protein expressions of ZO-1, N-cadherin, E-cadherin, vimentin, PPAR- $y$ and HMGB1 were examined by western blot. (B, C, D, E, F, G) Quantitative analyses of EMT markers, PPAR-Y and HMGB1. Data were expressed as mean \pm SD. *P < 0.05 .

\section{Expression of EMT markers in ECRSwNP and control tissues in western blots}

The epithelial markers ZO-1 and E-cadherin were down-regulated in ECRSwNP compared with control, whereas the mesenchymal markers $\mathrm{N}$-cadherin and vimentin were up-regulated in ECRSwNP compared with control. Expression of HMGB1 was obvious in ECRSwNP while expression of PPAR- $\gamma$ was obvious in control tissues (Fig. 3A). Quantitative analyses of protein expression levels of $\mathrm{N}$-cadherin, E-cadherin, vimentin, PPAR- $\gamma$ and HMGB1 in the western blot was significantly different $(\mathrm{P}<0.05)$ (Fig. 3C, D, E, F, G). Visual observation of the band confirmed that the expression of ZO-1 was lower in ECRSwNP tissues, but there was no significant statistical difference $(\mathrm{ZO}-1, \mathrm{P}=0.1048)$ (Fig. 3B). 


\section{RhHMGB1 promoted EMT in ECRSwNP cells}

EMT markers were detected in rhHMGB1incubated primary human nasal epithelial cells from ECRSwNP tissues via western blot. We found that rhHMGB1 can significantly decrease the epithelial markers E-cadherin and ZO-1, and increase the mesenchymal markers $\mathrm{N}$-cadherin and vimentin in ECRSwNP cells in a dose-dependent fashion (Fig. 4A). RhHMGB1 (500ng/ml) induced Changes in the expression of EMT-related proteins and there was significantly different $(\mathrm{P}<0.05)$. Additionally, cells incubated with rhHMGB1 underwent obvious morphological changes in comparison with the control group. The number of cells and the length of the pseudopodia increased in direct proportion to increased incubation time. This change may confer upon the cells a greater ability to migrate (Fig. 4C).

\section{Rosiglitazone inhibited rhHMGB1-induced EMT}

After incubation with rhHMGB1 for $48 \mathrm{~h}$, the expression of the intercellular adhesion molecule ZO-1 was decreased and vimentin was increased, whereas the addition of ROG $(20 \mu \mathrm{M})$ after incubation with rhHMGB1 $(500 \mathrm{ng} / \mathrm{ml})$ for $30 \mathrm{~min}$ enhanced the expression of ZO-1 but weaken expression of vimentin in confocal microscopic examination (Fig. 5A). RhHMGB1 down-regulated the expression of ZO-1 and E-cadherin and up-regulated the expression of $\mathrm{N}$-cadherin and vimentin, while the agonist of PPAR- $y$, ROG restored this change (Fig. 5B). The inhibitory effect of ROG on rhHMGB1-induced EMT was statistically significant (Fig. 5C).

\section{ROG inhibited LPS induced generation of HMGB 1 and suppressed the following EMT}

LPS increased HMGB1 expression in a dose-dependent manner. Both $1 \mu \mathrm{g} / \mathrm{ml}$ and $2 \mu \mathrm{g} / \mathrm{ml}$ can significantly promote the expression of HMGB1 and there was significant different $((\mathrm{P}<0.05)$ (Fig. $6 \mathrm{~A})$. LPS $(2 \mu \mathrm{g} / \mathrm{ml})$ induced the generation of HMGB1, while the agonist of PPAR- $\gamma($ ROG, $20 \mu \mathrm{M})$ reversed the expression of HMGB1 (Fig. 6B). Incubated ECRSwNP cells with LPS $(2 \mu \mathrm{g} / \mathrm{ml})$ induced down-regulated expression of ZO-1 and E-cadherin and up-regulated expression of vimentin and $\mathrm{N}$-cadherin. ROG restored this change (Fig. 6C). The difference of EMT markers expression was statistically significant after intervention with LPS (Fig. 6D).
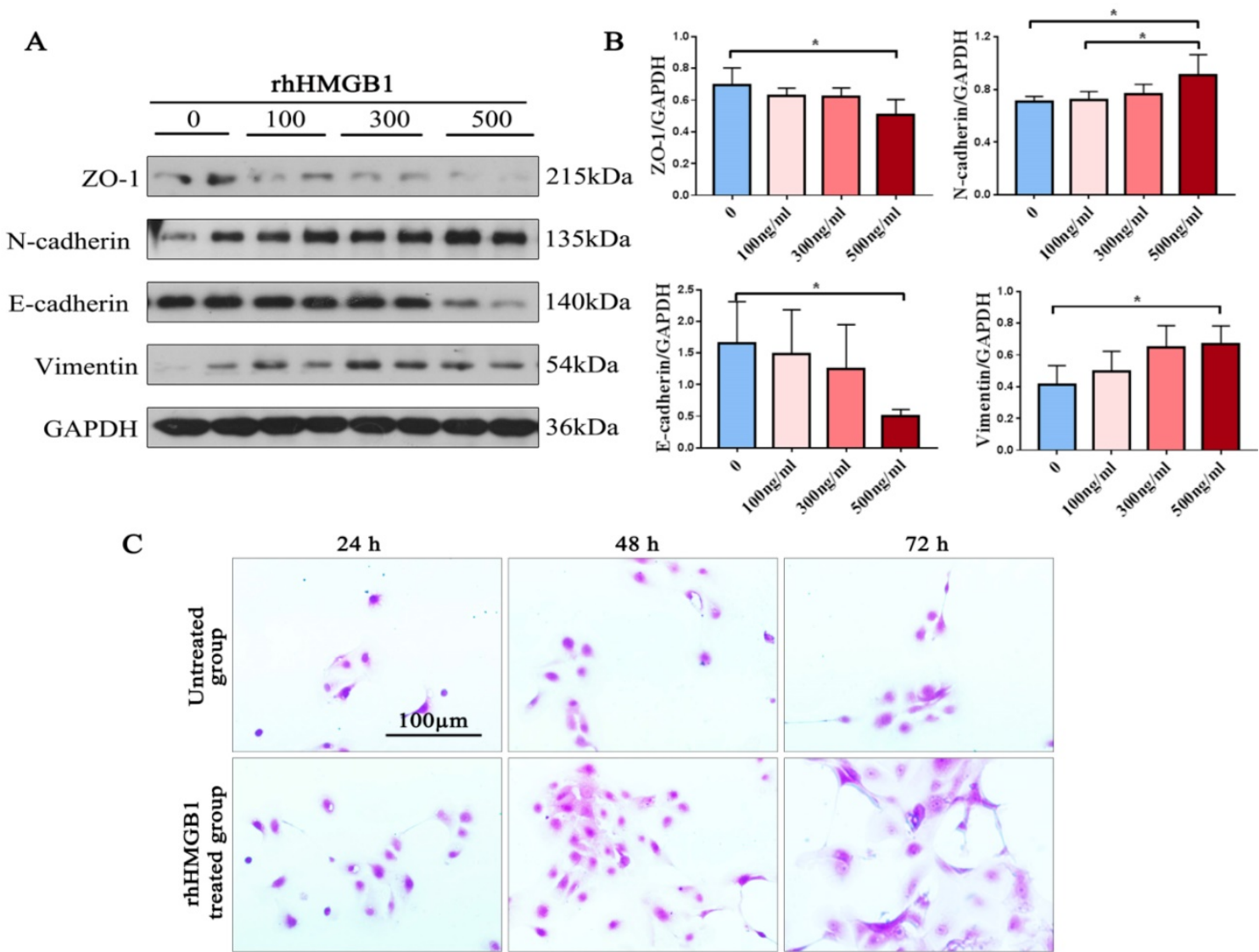

Figure 4. Expression of EMT markers in preliminary NP cells. (A) Western blot assay was performed to detect the expression of ZO-1, N-cadherin, E-cadherin, vimentin and GAPDH in primary ECRSwNP cells after treatment with dose-dependent rhHMGBI(ng/ml). (B) Quantitative analyses of expression levels of EMT markers in primary ECRSwNP cells. Data were expressed as mean \pm SD. $* \mathrm{P}<0.05$. (C) Cell morphology in the induction group (rhHMGB1: $500 \mathrm{ng} / \mathrm{ml}$ ) and the control group at 24,48 , and $72 \mathrm{~h}$. Cells were stained with crystal violet. Bar, $100 \mu \mathrm{m}$. 


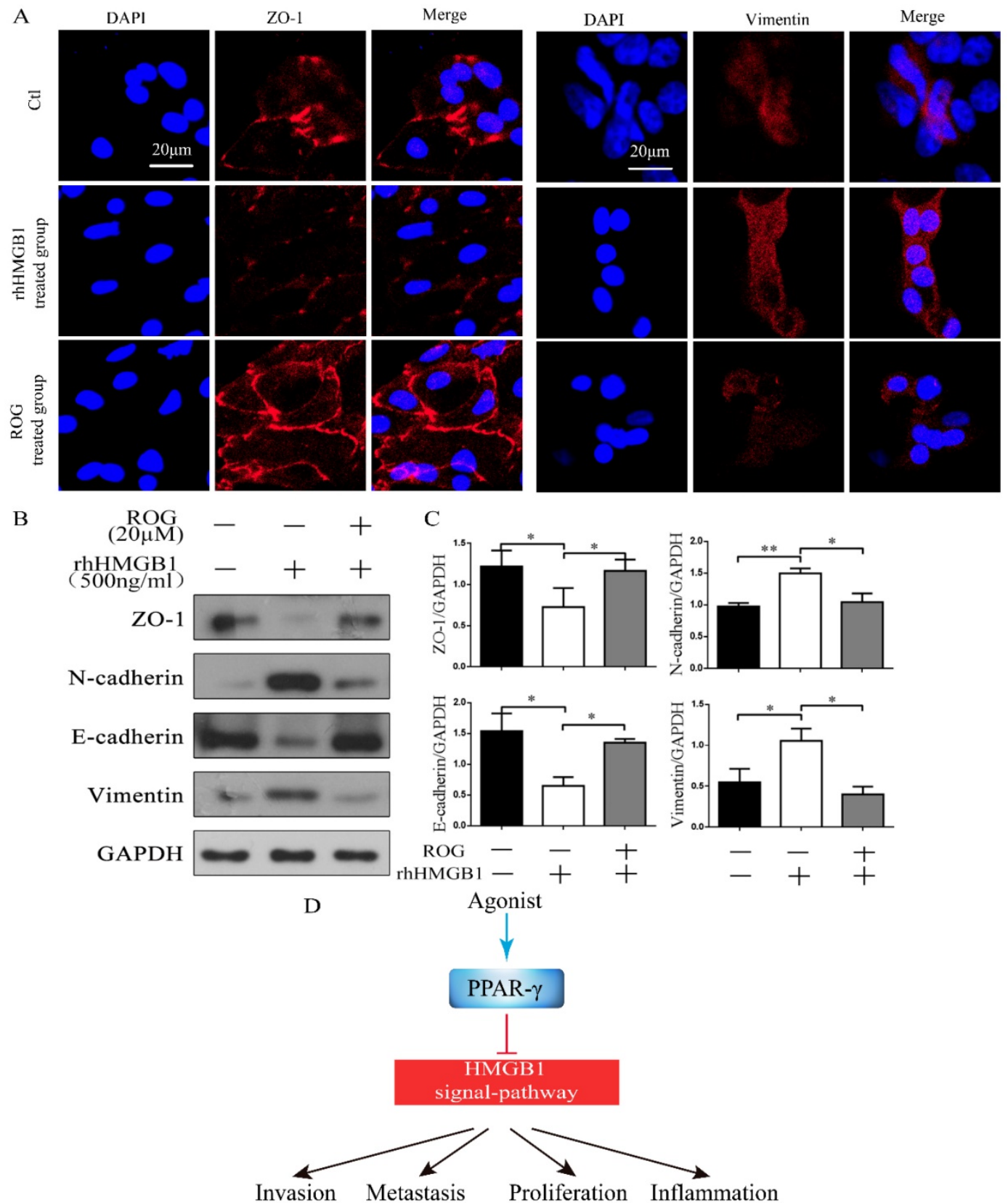

Figure 5. ROG inhibited rhHMGB 1 -induced EMT. (A) Confocal microscopic examination of ZO-1 and vimentin in different groups of ECRSwNP cells. Scale bar, $20 \mu \mathrm{m}$. (B) Effect of ROG $(20 \mu \mathrm{M})$ on the changes of EMT markers expression in ECRSwNP cells. Cells were cultured with or without rhHMGB1 (500ng/ml). (C) Quantitative analyses of ZO-1, N-cadherin, E-cadherin and vimentin. Data were expressed as mean \pm SD. $* P<0.05 * * P<0.01$. (D) Agonist of PPAR-y inhibited HMGB1-induced EMT.

\section{Discussion}

Inflammation and tissue remodeling are major morbidity factors in CRSwNP and there are some links between them. According to Hellquist's classification, the histological hallmarks of ECRSwNP contained edematous stroma, hyperplasia goblet cells, thickened basement membrane and numerous eosinophil cells while nonECRSwNP instead of more fibrosis tissues and infiltrate more lymphocyte cells [30]. There are positive correlations between edema and eosinophilic inflammation and between fibrosis and neutrophilic inflammation in CRSwNP [31-33]. So clinically, ECRSwNP appears friable, readily disintegrate, whereas nonECRSwNP is not edematous and instead of density tissues and pathologically, nonECRSwNP is distinguished by vigorous glandular hypertrophy compared with ECRSwNP [33,34]. About the mechanism of tissue restructuring, EMT plays an important role. EMT, or transformation from epithelial to mesenchymal states, which functions in embryonic development, inflammation, wound healing, and carcinoma, has also been reported to be involved in the tissue remodeling of CRSwNP [35,36]. 


\section{A}

HMGB 1

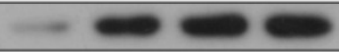

GAPDH

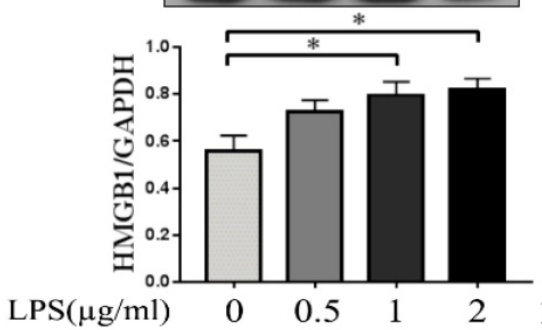

$\operatorname{LPS}(\mu \mathrm{g} / \mathrm{ml})$

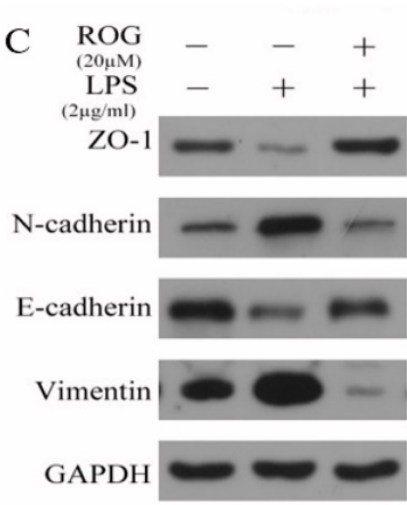

D
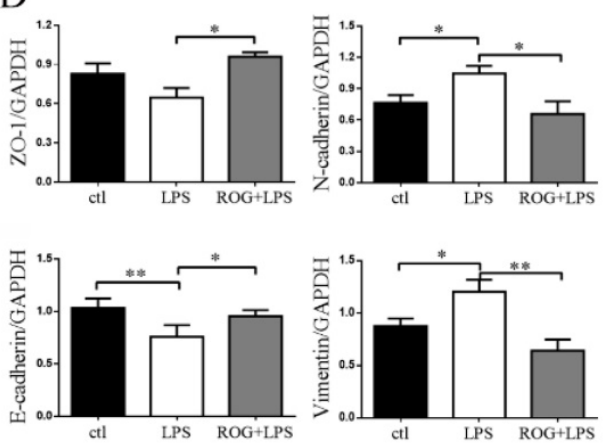

Figure 6. ROG inhibited LPS-induced EMT via HMGB1. (A) Effect of dose-dependent LPS on the expression of HMGB1. Cells were cultured with or without LPS. (B) Effect of ROG on the changes in HMGB1 expression with LPS. (C) Effect of ROG on the changes of EMT markers expression in ECRSwNP cells. Cells were cultured with or without LPS. (D) Quantitative analyses of ZO-1, N-cadherin, E-cadherin and vimentin. Data were expressed as mean \pm SD. $* \mathrm{P}<0.05 * * \mathrm{P}<0.01$.

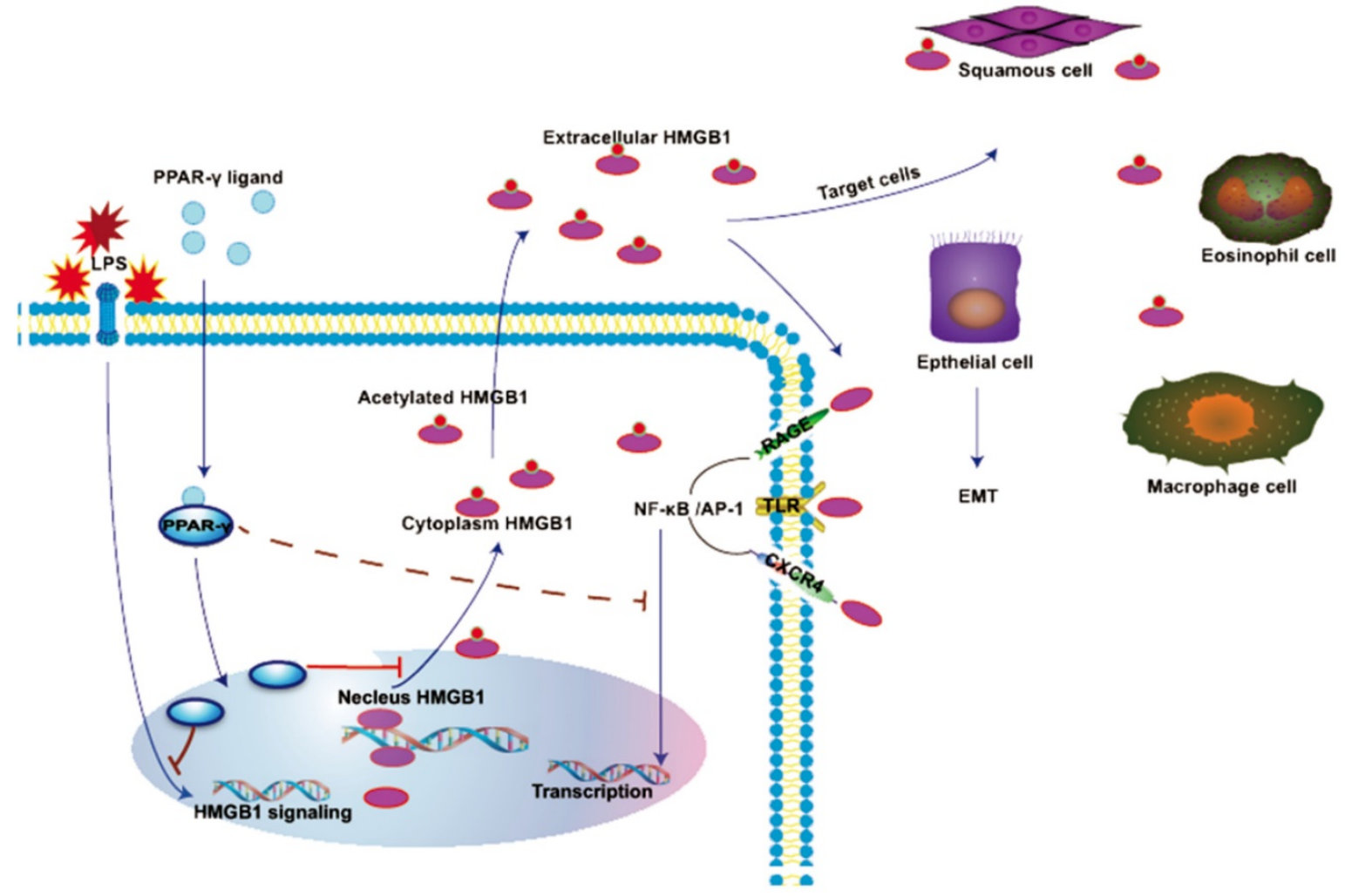

Figure 7. In normal conditions, HMGB1 is mainly localized in the nucleus in a non-acetylated form. HMGB1 binds RAGE, TLRs, or CXCR4 to induce NF-KB activation. NF-KB translocate to the nucleus and cause EMT in several cells. HMGBI is actively secreted by LPS-stimulated cells and translocated to the cytoplasm or extracellular space. The ligand of PPAR- $\gamma$ inhibited generation and translocation of HMGB1 stimulated by LPS, whereas the effect of rhHMGB1 is also inhibited by the agonist of PPAR-y. 
Many factors through different pathway regulate EMT, such as TGF- $\beta 1 / S M A D$, PI3K/AKT, MARK/ERK, and Wnt/ $\beta$-catenin signaling pathway to achieve the purpose of organizing tissue remodeling. Although TGF- $\beta 1$ was the most active player in pathogenesis of EMT, it was belongs to Th1 and Th3 cytokines and its expression in ECRSwNP was not obvious compared with non-ECRSwNP [37]. In previous studies, the expression trend of TGF- $\beta 1$ in CRSsNP, non-ECRSwNP and ECRSwNP is gradually declining [38-40]. And that, the EMT in ECRSwNP was more pronounced than in non-ECRSwNP. There must be other related factors causing the occurrence of EMT in ECRSwNP. In exploring the possible factors of inducing inflammation and tissue remodeling of ECRSwNP, which has the characteristics of abundant eosinophil infiltration, we found that the survival, migration, adhesion, and degranulation of eosinophils was depend to a great extent on HMGB1 [41]. Furthermore, varying expression patterns of HMGB1 have been observed in patients with asthma, COPD, endometrial carcinoma, bladder cancer, and lung cancer, and the pathogenesis of all has been considered to be importantly related to EMT [42-44]. In present study, HMGB1 was up-regulated in ECRSwNP tissues compared with control tissues. It's Consistent with previous studies. For the expression of HMGB1 in ECRSwNP was the highest among ECRSwNP, non-ECRSwNP, CRSsNP and normal tissues in previous studies, we thought HMGB1 has an important effect on the occurrence of EMT in ECRSwNP [41,45]. Moreover, we investigated the location of HMGB1. Our IHC assay revealed that cytoplasmic staining of HMGB1 was pronounced in the ECRSwNP tissues compared with control tissues. This result is supported by previous research in which the pro-inflammatory function of extracellular HMGB1 was elucidated [46].

HMGB1, a non-histone nuclear protein, regulates a number of key DNA events, such as nucleosome stability and sliding, genome chromatinization, DNA binding, DNA bending, and repairs [47-49]. Schaefer et al. proved that HMGB1 induces EMT through the RAGE and the PI3K/AKT/GSK3 $\beta / \beta$-catenin signaling pathway in human airway epithelial cells [50]. In the process of EMT, the expression of epithelial markers decreases, whereas the expression of mesenchymal markers increases. In our study, the expression of mesenchymal markers such as $\mathrm{N}$-cadherin and vimentin increased, and the expression of E-cadherin and ZO-1 decreased in ECRSwNP tissues compared with the control tissues. The evidence indicated the occurrence of EMT in ECRSwNP. In view of the positive regulation between HMGB1 and eosinophils [51], and the role of HMGB1 in causing EMT, we believe that EMT is partially induced by HMGB1 in ECRSwNP and that the inhibition of HMGB1 expression may help to inhibit the EMT process. In present study, we found that the presence of EMT in ECRSwNP was accompanied by an increase of HMGB1 expression obviously. As an in vitro test to confirm the role of HMGB1 in ECRSwNP, we treated cells which were isolated from ECRSwNP tissues with rhHMGB1. We found that rhHMGB1 induced EMT dose-dependently. Furthermore, rhHMGB1 treatment induced morphological changes in ECRSwNP cells. Confocal microscopic assay also confirmed the function of HMGB1-induced EMT.

PPAR- $\gamma$, which belongs to a nuclear hormone receptor superfamily, has the function of modulating lipid/lipoprotein metabolism, cell cycle progression, cellular proliferation, and differentiation after binding to ligand [52,53]. It was reportedly has an anti-inflammatory function and has potential value in the treatment of COPD, idiopathic pulmonary fibrosis, asthma, acute lung injury and acute respiratory distress syndrome [29,54-56]. Previous research has indicated multiple effects of PPAR ligands, such as telmisartan, troglitazone, rosiglitazone, and pioglitazone, suppressing the biological actions of HMGB1 [57-59]. Rosiglitazone, a member of the thiazolidinedione class, has been reported to have a suppressive effect on LPS-induced acute injury via inhibition of HMGB1 through RAGE/NF- $\kappa$ B and MAPK pathways [60]. In order to explore the effect of ROG on exogenous rhHMGB1, we used ROG to treat the cells which were interfering with rhHMGB1. We found that ROG administration reversed the effect of rhHMGB1 on EMT in ECRSwNP cells. To explore the effect of ROG on endogenous HMGB1, we used LPS to stimulate the expression of HMGB1. Many previous literatures support the release of HMGB1 and the subsequent release of inflammatory mediators were stimulated by LPS $[61,62]$. Consistent with previous studies, we found LPS increased expression of HMGB1 combined with amplification of EMT. Incubating cells with ROG, the results showed that ROG inhibited LPS-induced HMGB1 release and followed the inhibition of EMT in cells isolated from ECRSwNP tissues. These results demonstrate that the agonist of PPAR- $\gamma$ has the same effect on extracellular HMGB1 and endogenous HMGB1. It can inhibit the biological action of HMGB1 at different levels.

The limitation of the present study is that the sample size of ECRSwNP patients and control subjects is small. In addition, this finding was specific on ECRSwNP, which demonstrate the effect of HMGB1 on pathogenesis of ECRSwNP, but was not differentiated into ECRSwNP, non-ECRSwNP, 
CRSsNP and normal tissues, which may illustrate the difference of HMGB1 in the pathogenesis of chronic inflammatory disease in the nasal cavity. Thus, further studies involving larger groups of patients and classified into different endotypes are needed in the future.

In summary, our research found high expression of HMGB1 in ECRSwNP tissues and showed that HMGB1 can induce EMT in ECRSwNP cells partially. The agonist of PPAR- $\gamma$ inhibits HMGB1-induced EMT procession. The ligand of PPAR- $\gamma$ may be a potential agent for the treatment of ECRSwNP.

\section{Acknowledgments}

We thank all the study participants, and the patients who provided the samples for this study. This paper was supported by the National Natural Science Foundation of China (No. 81873700).

\section{Competing Interests}

The authors have declared that no competing interest exists.

\section{References}

1. Van Crombruggen K, Zhang N, Gevaert P, Tomassen P, Bachert C. Pathogenesis of chronic rhinosinusitis: inflammation. J Allergy Clin Immunol. 2011; 128:728-32.

2. Brescia G, Zanotti C, Parrino D, Barion U, Marioni G. Nasal polyposis pathophysiology: Endotype and phenotype open issues. Am J Otolaryngol. 2018; 39:441-4.

3. Marioni G, Zanotti C, Brescia G. Chronic rhinosinusitis with nasal polyps in the elderly: Assessing current evidence. ALLERGY ASTHMA PROC. 2018; 39:9-13.

4. Hong SN, Lee WH, Lee $\mathrm{SH}$, Rhee CS, Lee $\mathrm{CH}$, Kim JW. Chronic rhinosinusitis with nasal polyps is associated with chronic otitis media in the elderly. Eur Arch Otorhinolaryngol. 2017; 274:1463-70.

5. Brescia G, Barion U, Pedruzzi B, Cinetto F, Giacomelli L, Pendolino AL, et al. Sinonasal polyposis in the elderly. AM J RHINOL ALLERGY. 2016; 30:153-6.

6. Cao PP, Zhang YN, Liao B, Ma J, Wang BF, Wang H, et al. Increased local IgE production induced by common aeroallergens and phenotypic alteration of mast cells in Chinese eosinophilic, but not non-eosinophilic, chronic rhinosinusitis with nasal polyps. CLIN EXP ALLERGY. 2014; 44:690-700.

7. Lou H, Zhang N, Bachert C, Zhang L. Highlights of eosinophilic chronic rhinosinusitis with nasal polyps in definition, prognosis, and advancement. Int Forum Allergy Rhinol. 2018; 8:1218-1225

8. Wang H, Pan L, Liu Z. Neutrophils as a Protagonist and Target in Chronic Rhinosinusitis. Clin Exp Otorhinolaryngol. 2019; doi:10.21053/ceo.2019.00654

9. Liu C, Yan B, Qi S, Zhang Y, Zhang L, Wang C. Predictive Significance of Charcot-Leyden Crystals for Eosinophilic Chronic Rhinosinusitis with Nasal Polyps. AM J RHINOL ALLERGY. 20191651832998.

10. Wang H, Li ZY, Jiang WX, Liao B, Zhai GT, Wang N, et al. The activation and function of IL-36gamma in neutrophilic inflammation in chronic rhinosinusitis. J Allergy Clin Immunol. 2018; 141:1646-58.

11. Wang X, Zhang N, Bo M, Holtappels G, Zheng M, Lou H, et al. Diversity of $\mathrm{TH}$ cytokine profiles in patients with chronic rhinosinusitis: A multicenter study in Europe, Asia, and Oceania. J Allergy Clin Immunol. 2016; 138:1344-53.

12. Cao PP, Wang ZC, Schleimer RP, Liu Z. Pathophysiologic mechanisms of chronic rhinosinusitis and their roles in emerging disease endotypes. Ann Allergy Asthma Immunol. 2019; 122:33-40.

13. Jiang WX, Cao PP, Li ZY, Zhai GT, Liao B, Lu X, et al. A retrospective study of changes of histopathology of nasal polyps in adult Chinese in central China. RHINOLOGY. 2019; 57:261-7.
14. Cavone L, Cuppari C, Manti S, Grasso L, Arrigo T, Calamai L, et al. Increase in the Level of Proinflammatory Cytokine HMGB1 in Nasal Fluids of Patients with Rhinitis and its Sequestration by Glycyrrhizin Induces Eosinophil Cell Death. Clin Exp Otorhinolaryngol. 2015; 8:123-8.

15. Chen S, Wang Y, Gong G, Chen J, Niu Y, Kong W. Ethyl pyruvate attenuates murine allergic rhinitis partly by decreasing high mobility group box 1 release. Exp Biol Med (Maywood). 2015; 240:1490-9.

16. Ferhani N, Letuve S, Kozhich A, Thibaudeau O, Grandsaigne M, Maret $\mathrm{M}$, et al. Expression of high-mobility group box 1 and of receptor for advanced glycation end products in chronic obstructive pulmonary disease. Am J Respir Crit Care Med. 2010; 181:917-27.

17. Bellussi LM, Cocca S, Chen L, Passali FM, Sarafoleanu C, Passali D. Rhinosinusal Inflammation and High Mobility Group Box 1 Protein: A New Target for Therapy. ORL J Otorhinolaryngol Relat Spec. 2016; 78:77-85.

18. Tang Z, Jiang M, Ou-Yang Z, Wu H, Dong S, Hei M. High mobility group box 1 protein (HMGB1) as biomarker in hypoxia-induced persistent pulmonary hypertension of the newborn: a clinical and in vivo pilot study. INT J MED SCI. 2019; 16:1123-31.

19. Chen YC, Statt S, Wu R, Chang HT, Liao JW, Wang CN, et al. High mobility group box 1-induced epithelial mesenchymal transition in human airway epithelial cells. Sci Rep. 2016; 6:18815.

20. Liu PL, Liu WL, Chang JM, Chen YH, Liu YP, Kuo HF, et al. MicroRNA-200c inhibits epithelial-mesenchymal transition, invasion, and migration of lung cancer by targeting HMGB1. PLOS ONE. 2017;12: e180844.

21. Lee YZ, Yap HM, Shaari K, Tham CL, Sulaiman MR, Israf DA. Blockade of Eosinophil-Induced Bronchial Epithelial-Mesenchymal Transition with a Geranyl Acetophenone in a Coculture Model. FRONT PHARMACOL. 2017; 8:837.

22. Yasukawa A, Hosoki K, Toda M, Miyake Y, Matsushima Y, Matsumoto $\mathrm{T}$, et al. Eosinophils promote epithelial to mesenchymal transition of bronchial epithelial cells. PLOS ONE. 2013;8: e64281.

23. Konnecke M, Burmeister M, Pries R, Boscke R, Bruchhage KL, Ungefroren $\mathrm{H}$, et al. Epithelial-Mesenchymal Transition in Chronic Rhinosinusitis: Differences Revealed Between Epithelial Cells from Nasal Polyps and Inferior Turbinates. Arch Immunol Ther Exp (Warsz). 2017; 65:157-73.

24. Hay ED. An overview of epithelio-mesenchymal transformation. Acta Anat (Basel). 1995; 154:8-20.

25. Hwang JS, Kang ES, Ham SA, Yoo T, Lee H, Paek KS, et al. Activation of peroxisome proliferator-activated receptor gamma by rosiglitazone inhibits lipopolysaccharide-induced release of high mobility group box 1. Mediators Inflamm. 2012; 2012:352807.

26. Li M, Li Z, Sun $X$, Yang L, Fang $P$, Liu $Y$, et al. Heme oxygenase-1/p21WAF1 mediates peroxisome proliferator-activated receptor-gamma signaling inhibition of proliferation of rat pulmonary artery smooth muscle cells. FEBS J. 2010; 277:1543-50.

27. Yin H, Li X, Gong Q, Jin X, Gu H, Yuan B, et al. Heme oxygenase-1 upregulation improves lipopolysaccharide-induced acute lung injury involving suppression of macrophage migration inhibitory factor. MOL IMMUNOL. 2010; 47:2443-9.

28. Ying S, Xiao X, Chen T, Lou J. PPAR Ligands Function as Suppressors That Target Biological Actions of HMGB1. PPAR RES. 2016; 2016:2612743

29. Hwang JS, Kang ES, Ham SA, Yoo T, Lee H, Paek KS, et al. Activation of peroxisome proliferator-activated receptor gamma by rosiglitazone inhibits lipopolysaccharide-induced release of high mobility group box 1. Mediators Inflamm. 2012; 2012:352807.

30. Hellquist HB. Nasal polyps update. Histopathology. ALLERGY ASTHMA PROC. 1996; 17:237-42.

31. Cao PP, Li HB, Wang BF, Wang SB, You XJ, Cui YH, et al. Distinct immunopathologic characteristics of various types of chronic rhinosinusitis in adult Chinese. J Allergy Clin Immunol. 2009; 124:478-84, 481-4.

32. Wang ZC, Yao Y, Wang N, Liu JX, Ma J, Chen CL, et al. Deficiency in interleukin-10 production by M2 macrophages in eosinophilic chronic rhinosinusitis with nasal polyps. Int Forum Allergy Rhinol. 2018.

33. Payne SC, Early SB, Huyett P, Han JK, Borish L, Steinke JW. Evidence for distinct histologic profile of nasal polyps with and without eosinophilia. LARYNGOSCOPE. 2011; 121:2262-7.

34. Shi LL, Xiong P, Zhang L, Cao PP, Liao B, Lu X, et al. Features of airway remodeling in different types of Chinese chronic rhinosinusitis are associated with inflammation patterns. ALLERGY. 2013; 68:101-9.

35. Könnecke M, Burmeister M, Pries R, Böscke R, Bruchhage K, Ungefroren $\mathrm{H}$, et al. Epithelial - Mesenchymal Transition in Chronic Rhinosinusitis: Differences Revealed Between Epithelial Cells from Nasal Polyps and Inferior Turbinates. ARCH IMMUNOL THER EX. 2017; 65:157-73. 
36. Lamouille S, Xu J, Derynck R. Molecular mechanisms of epithelial mesenchymal transition. NAT REV MOL CELL BIO. 2014; 15:178-96.

37. Hsieh CC, Peng WH, Tseng HH, Liang SY, Chen LJ, Tsai JC. The Protective Role of Garlic on Allergen-Induced Airway Inflammation in Mice. Am J Chin Med. 2019; 47:1099-112.

38. Li X, Li C, Zhu G, Yuan W, Xiao ZA. TGF-beta1 Induces Epithelial-Mesenchymal Transition of Chronic Sinusitis with Nasal Polyps through MicroRNA-21. Int Arch Allergy Immunol. 2019; 179:304-19.

39. Kuhar HN, Tajudeen BA, Mahdavinia M, Gattuso P, Ghai R, Batra PS. Inflammatory infiltrate and mucosal remodeling in chronic rhinosinusitis with and without polyps: structured histopathologic analysis. Int Forum Allergy Rhinol. 2017; 7:679-89.

40. Van Bruaene N, Bachert C. Tissue remodeling in chronic rhinosinusitis. Curr Opin Allergy Clin Immunol. 2011;11:8-11.

41. Chen D, Mao M, Bellussi LM, Passali D, Chen L. Increase of high mobility group box chromosomal protein 1 in eosinophilic chronic rhinosinusitis with nasal polyps. Int Forum Allergy Rhinol. 2014; 4:453-62.

42. Watanabe T, Asai K, Fujimoto H, Tanaka H, Kanazawa H, Hirata K. Increased levels of HMGB-1 and endogenous secretory RAGE in induced sputum from asthmatic patients. Respir Med. 2011; 105:519-25.

43. Hou C, Zhao H, Liu L, Li W, Zhou X, Lv Y, et al. High mobility group protein B1 (HMGB1) in Asthma: comparison of patients with chronic obstructive pulmonary disease and healthy controls. MOL MED. 2011; 17:807-15.

44. Luan X, Ma C, Wang P, Lou F. HMGB1 is negatively correlated with the development of endometrial carcinoma and prevents cancer cell invasion and metastasis by inhibiting the process of epithelial-to-mesenchymal transition. Onco Targets Ther. 2017; 10:1389-402.

45. Xu J, Lee JW, Park SK, Lee SB, Yoon YH, Yeon SH, et al. Toll-like receptor 9 ligands increase type I interferon induced B-cell activating factor expression in chronic rhinosinusitis with nasal polyposis. CLIN IMMUNOL. 2018; 197:19-26.

46. Bianchi ME. HMGB1 loves company. J Leukoc Biol. 2009; 86:573-6.

47. Bonne-Andrea C, Harper F, Puvion E, Delpech M, De Recondo AM. Nuclear accumulation of HMG1 protein is correlated to DNA synthesis. BIOL CELL. 1986; 58:185-94.

48. Feser J, Truong D, Das C, Carson JJ, Kieft J, Harkness T, et al. Elevated histone expression promotes life span extension. MOL CELL. 2010; 39:724-35.

49. Javaherian K, Liu JF, Wang JC. Nonhistone proteins HMG1 and HMG2 change the DNA helical structure. SCIENCE. 1978; 199:1345-6.

50. Lou Y, Diao L, Cuentas ERP, Denning WL, Chen L, Fan YH, et al. Epithelial-Mesenchymal Transition Is Associated with a Distinct Tumor Microenvironment Including Elevation of Inflammatory Signals and Multiple Immune Checkpoints in Lung Adenocarcinoma. CLIN CANCER RES. 2016; 22:3630-42.

51. Nesi RT, Kennedy-Feitosa E, Lanzetti M, Avila MB, Magalhaes CB, Zin WA, et al. Inflammatory and Oxidative Stress Markers in Experimental Allergic Asthma. INFLAMMATION. 2017; 40:1166-76.

52. Moras D, Gronemeyer H. The nuclear receptor ligand-binding domain: structure and function. CURR OPIN CELL BIOL. 1998; 10:384-91.

53. Li J, Guo C, Wu J. 15-Deoxy--(12,14)-Prostaglandin J2 (15d-PGJ2), an Endogenous Ligand of PPAR-gamma: Function and Mechanism. PPAR RES. 2019; 2019:7242030.

54. Schaefer MB, Pose A, Ott J, Hecker M, Behnk A, Schulz R, et al. Peroxisome proliferator-activated receptor-alpha reduces inflammation and vascular leakage in a murine model of acute lung injury. EUR RESPIR J. 2008; 32:1344-53.

55. Honda K, Marquillies P, Capron M, Dombrowicz D. Peroxisome proliferator-activated receptor gamma is expressed in airways and inhibits features of airway remodeling in a mouse asthma model. J Allergy Clin Immunol. 2004; 113:882-8.

56. Krishnamoorthy S, Recchiuti A, Chiang N, Fredman G, Serhan CN. Resolvin D1 receptor stereoselectivity and regulation of inflammation and proresolving microRNAs. AM J PATHOL. 2012; 180:2018-27.

57. Goebel M, Clemenz M, Staels B, Unger T, Kintscher U, Gust R. Characterization of new PPARgamma agonists: analysis of telmisartan's structural components. CHEMMEDCHEM. 2009; 4:445-56.

58. Bonaldi T, Talamo F, Scaffidi P, Ferrera D, Porto A, Bachi A, et al Monocytic cells hyperacetylate chromatin protein HMGB1 to redirect it towards secretion. EMBO J. 2003; 22:5551-60.

59. Gao M, Hu Z, Zheng Y, Zeng Y, Shen X, Zhong D, et al. Peroxisome proliferator-activated receptor gamma agonist troglitazone inhibits high mobility group box 1 expression in endothelial cells via suppressing transcriptional activity of nuclear factor kappaB and activator protein 1 . SHOCK. 2011; 36:228-34.
60. Wang G, Liu L, Zhang Y, Han D, Liu J, Xu J, et al. Activation of PPARgamma attenuates LPS-induced acute lung injury by inhibition of HMGB1-RAGE levels. EUR J PHARMACOL. 2014; 726:27-32.

61. Kim HM, Kim YM. HMGB1: LPS Delivery Vehicle for Caspase-11-Mediated Pyroptosis. IMMUNITY. 2018; 49:582-4.

62. Hagiwara S, Iwasaka H, Noguchi T. Nafamostat mesilate inhibits the expression of HMGB1 in lipopolysaccharide-induced acute lung injury. J ANESTH. 2007; 21:164-70. 